\title{
Plasma spray fabrication of near-net-shape ceramic objects
}

\author{
Shangzhao Shi and Jiann-Yang Hwang* \\ Institute of Materials Processing, Department of Materials Science and Engineering \\ Michigan Technological University, \\ Houghton, MI 49931
}

\begin{abstract}
Among near net shape approaches, plasma spray deposition has its own advantages. It can perform ultrahigh temperature heating, produce components with layered compositions and structures, and fabricate thin-wall and large diameter objects. In this paper, the microstructural characteristics and their influential factors were reviewed in the light of the plasma spray forming process.
\end{abstract}

\section{Introduction}

Plasma spray deposition is a new technique for near-net-shape fabrication. Figure 1-4 show a few typical objects formed by the plasma spray technique ${ }^{1-4}$. The most notable technical advantage of plasma spray forming is its capacity for ultrahigh-temperature heating. Plasma flames for thermal spray can produce temperatures around 7,000 to $20,000 \mathrm{~K}$ that is far above the melting temperature (and vapor temperature) of any known materials. The feasibility of near-net-shape manufacturing of refractory metals, such as tungsten and tungsten-rhenium alloys ${ }^{5}$, and ceramics, such as $\mathrm{HfB}_{2}, \mathrm{HfC}$ and $\mathrm{HfN}^{6}$ as well as $\mathrm{ZrB}_{2}-\mathrm{SiC}$ composites ${ }^{7}$ that are difficult to fabricate with other approaches, has been demonstrated with the plasma spray forming approach. Another advantage of this technique comes from its capability of fabricating components with alternate layers of different material compositions. Alumina-titania composite has been deposited containing $\mathrm{Al}_{2} \mathrm{O}_{3}(60 \mathrm{wt} \%)$ and $\mathrm{TiO}_{2}(40 \mathrm{wt} \%)$ as the alternate layers ${ }^{8}$. Nozzles, cones and cylinders were fabricated constituting metallic (nickel), ceramic (zirconia-8 wt.\% yttria) and layered composites with alternate layers of the ceramic and metallic materials ${ }^{9}$. Components with an yttria-stabilized-zirconia inner layer, CoNiCrAlY bond coat and IN-738LC outer layer were also produced $^{\mathbf{1 0}}$. The ability to make thin-wall and large diameter objects constitutes the further advantage of the plasma spray technique. An other example was the fabrication of a tapered alumina ring, which had a diameter of $500 \mathrm{~mm}$ and a wall thickness of $0.5 \mathrm{~mm}^{1}$. Such an object is difficult to handle in both the green body preparation and the high temperature processing if using the conventional approaches.

\section{The plasma spray forming process}

Near-net-shape forming using the plasma spray technique involves the simultaneous melting of powder and accelerating the molten particles for deposition on a substrate. Figure $\mathbf{5}$ shows a schematic of the plasma-spray-forming technique. As shown in the figure, the plasma spray gun comprises an anode and cathode. Plasma gas flows around the cathode and through the anode, which is shaped as a constricting nozzle. The nozzle creates an arc that ionizes the gas stream, forming the plasma with extremely high temperatures. Material in powder form is injected into the plasma flame where it melts and is accelerated to high speed. The molten material is directed toward the substrate, where it deposits and rapidly cools, forming the desired shape.

Figure 6 is a photograph of a plasma spray forming facility ${ }^{11}$, of which the substrate is a rotating mandrel. The mandrel usually has the negative figure of the desired shape. It also has a method for rapidly cooling, to increase the nucleation rate and obtain fine microstructure of the deposition. In order to release the deposited object from the mandrel, the mandrel should made from materials that have a substantial difference in thermal expansion from the deposited material.

\footnotetext{
* Author to whom correspondence should be addressed
} 


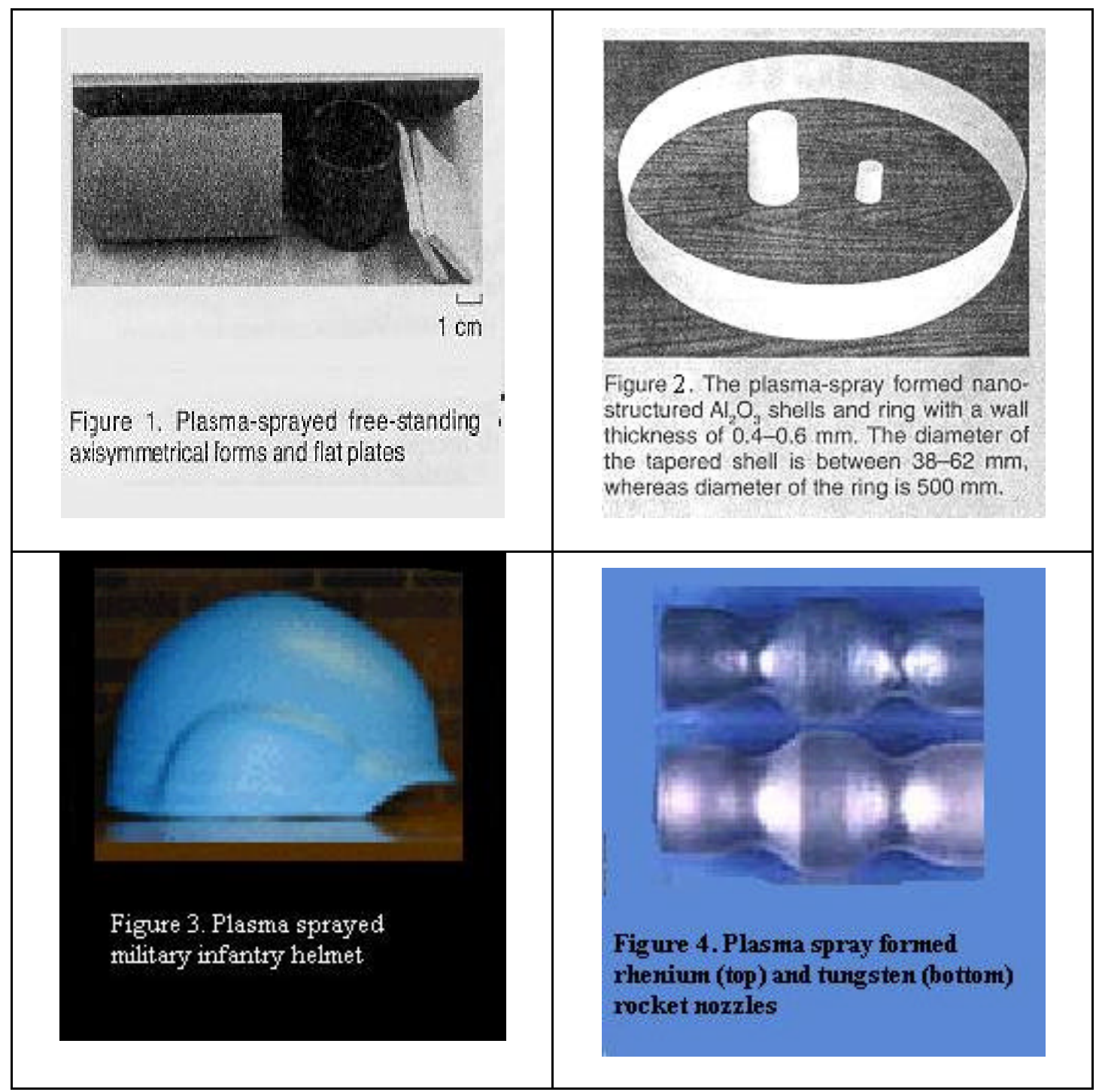

\section{Microstructural characteristics of the plasma sprayed deposit}

The plasma sprayed deposit is characterized as a layered structure'. As the plasma gun starts to scan, the substrate first intercepts the particles in the boundary region of the spray stream, collecting a large number of particles with low degree of melting. This entails formation of protrusions and depressions, which leads to the formation of porosity. As the gun moves, particles in the center-line of the spray cone that have a higher degree of melting are deposited on the top, forming layers with less porosity. Hence a coating of layered structure is developed when the deposition pattern is scanned over the substrate. 


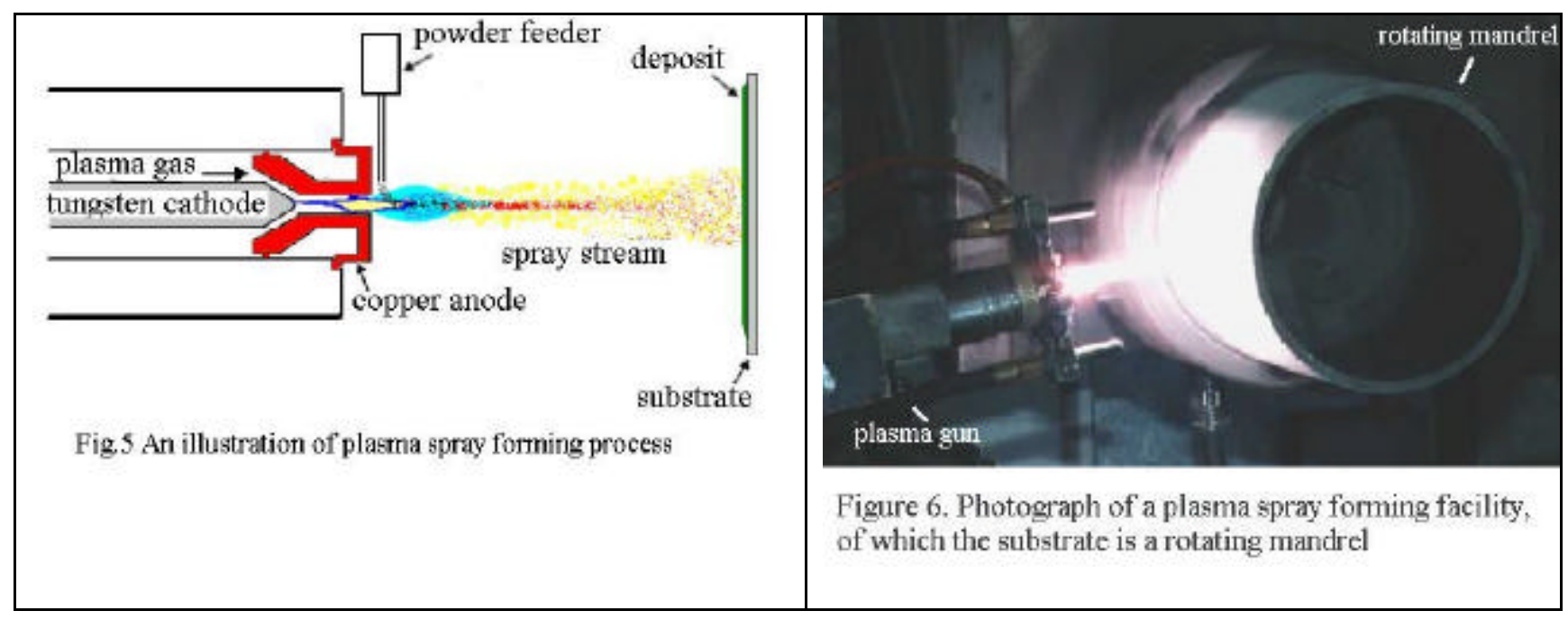

The microstructural units in the spray deposit are small disks called splats, which are formed by the spread and solidification of the high temperature molten/semimolten particles when they encounter the substrate at high velocity. The flattening ratio of the splat has been formulated by Madejki as follows ${ }^{\mathbf{1 2}}$ :

$$
\frac{D_{s}}{d_{p}}=1.2941\left(\frac{\rho v d_{p}}{\eta}\right)^{0.2}
$$

where $D_{s}$ is the splat diameter, $d_{p}$ is the particle (droplet) diameter, $\rho$ is the density, $v$ is the plasma velocity, $\eta$ is the kinetic viscosity and $D_{s} / d_{p}$ is defined as flattening ratio. Other researchers have proposed similar formulas for the formation of the splats except that they have replaced the coefficient with different numbers. The formula is based on the assumption that the substrate is smooth and preheated, and the splat has a regular disk shape. When the substrate temperature was low, such as room temperature, however, splat shapes were distorted. Kucuk et $\mathrm{al}^{13}$ determined the flattening ratio of yttria-partiallystabilized zirconia splats, which were formed on cold glass substrate and are irregularly shaped. Their experimental result was still in good agreement with the calculation from this formula.

The forces holding together the individually solidified splats in the deposit are key factors for achieving good strength of the formed objects. Gopalakrishnan et al examined the microstructure of the plasma sprayed alumina-titania ceramic composite. They found that at most places, good contact was established between the impacting splat and the underlying lamellae. But there were other places that reveal a multitude of flaws that are riddle with cracks and honeycombed with voids filled with air. Such microstructural defects, if not minimized, can doom the deposit when exposed to mechanical stress. They post-heat-treated the as-sprayed specimen at $1200^{\circ} \mathrm{C}$ and obtained a more densified structure, which doubled the strength of a spray-formed annular ring subjected to diametral compression tests (150 Mpa vs $75 \mathrm{Mpa})$. Higher temperature $\left(1400-1600^{\circ} \mathrm{C}\right)$ heat treatment, however, changed the layered structure to equi-axed structure and increased the porosity. Correspondingly, the higher temperature heat treatments deteriorated the strength to a great extent.

Agarwal et at modified microstructure of plasma spray-formed alumina objects by incorporation of nanosize alumina agglomerates (40 wt.\%) into commercial alumina powders $(15-45 \mu \mathrm{m}, 60 \mathrm{wt} . \%)$. Microscopic images showed fully melted coarse alumina grains surrounded by ultrafine grain structure. $\mathrm{Al}_{2} \mathrm{O}_{3}$ fine grains retained their nanostructure after plasma forming. The structure of the formed object is homogeneous and free from cracks. The porosity of the spray-deposited alumina was estimated to be 9 vol.\% using quantitative microscopy. The microhardness was 1,065 \pm 73 Vickers hardness number, which is higher than conventional alumina coatings in as-sprayed condition. 
Influences of the plasma spray parameters on the deposition behavior

Formula (1) indicates that the formation of splats depends on the plasma velocity. The velocity controls the time that the particles are exposed to the heating zone and the kinetic energy with which they impact the substrate. A sufficiently high-degree of melting particles and high-kinetic energy of particles in the plasma stream ensure the spread of the particles onto the substrate and formation into splats. Shaw et $a l^{\mathbf{1 4}}$ suggested the dependence of the particle melting on the plasma-processing parameter (IV/Ar), where IV is the electrical power (watts) and $\mathrm{Ar}$ is the primary gas flow rate. For nanostructured $\mathrm{Al}_{2} \mathrm{O}_{3}-13$ wt. $\% \mathrm{TiO}_{2}$ coatings, an IV/Ar ratio $>310$ is necessary to achieve a sufficiently higher degree of particles melting.

Kucuk et $a l^{15}$ suggested the most influential spray parameter that governs the in-flight behavior of the particles in the spray stream is the carrier gas flow rate. A particle injected from the feeder can either flow through the hot core of the plasma cone, or flow along the stream edge. Further more, they could bounce off from the plasma flow or cross over the plasma jet. The carrier gas flow rate determines the particle momentum and determines the trajectory of a particle injected into the plasma jet, which in turn determines the heated status (molten or unmolten) of the in-flight particles. For the $\mathrm{ZrO}_{2}-8 \mathrm{wt} \% \quad \mathrm{Y}_{2} \mathrm{O}_{3}$ powder with an average particle size of $80 \mu \mathrm{m}$, they found that a carrier gas flow rate of $3.5 \mathrm{~L} / \mathrm{min}$ is the ideal value, at which the particle flux central line coincides with the plasma jet axis. The particles injected with a carrier flow rate less than this value penetrate into the plasma jet to a certain extent, i.e., in such a way that they do not reach the plasma jet axis, but reside in the cooler zone of the jet before reaching the substrate. On the other hand, the particles that are injected with carrier gas flow rate higher than this value penetrate into the plasma sufficiently to cross the plasma jet axis and reside at a location where the temperature is lower than the core temperature.

The carrier gas flow rate is also influential on the deposition efficiency. The trends in the measured deposition efficiency value ${ }^{13}$ of $\mathrm{ZrO}_{2}-8 \mathrm{wt} \% \quad \mathrm{Y}_{2} \mathrm{O}_{3}$ powder were in good agreement with that in the measured percentage of molten/semimolten particles ${ }^{15}$. This is not surprising because the deposition efficiency in plasma spray processes strongly depends on the percentage of particles (molten/semimolten) with temperature higher than the melting point of the material.

Other factors that influence the deposition efficiency include torch power ${ }^{16,17}$, stand-off distance ${ }^{18}$, powder feeding rate ${ }^{\mathbf{1 9}}$ as well as the torch electrode condition ${ }^{\mathbf{2 0 , 2 1}}$. A rougher substrate surface enhances deposition efficiency due to improved mechanical adhesion between the substrate and the splat resulting from impinging and also creates a rougher surface for the secondary splats arriving on the top of the first splat layer ${ }^{13}$. A hollow sphere YSZ feedstock with high crust density yielded higher deposition efficiency than crushed YSZ, because hollow sphere particles provide more uniform temperature distribution ${ }^{22}$.

Particle size is also an important factor that influences the deposition behavior. At similar carrier gas flow rates, smaller particles have smaller momentum. They have less chance to flow through the hot core of the plasma cone. Although attempts to flow nanosize powder alone in plasma stream proved to be difficulty ${ }^{14}$, Agarwal et al made use of this phenomenon to retain in their plasma spray forming of alumina components the nanostructure of the ultrafine alumina particles ${ }^{6}$, which demonstrated the improvement of the deposit properties. In the mixture of bimodal particulate powders, micrometer size powder particles flow coherently through the hot zone of the plasma, whereas a larger fraction of nanosize powder does not flow through the hot core of the plasma due to their smaller size. Hence, a larger degree of melting occurs in coarse powder particles, whereas nanosize powder particles are partially melted or unmelted and trapped as overspray between the molten coarser particles.

\section{Summary}

Plasma spray has ultrahigh-temperature heating capability. It is especially suitable for near-net-shape fabrication of hard-to-form ceramic or metallic objects with layered structure and thin walls.

The primary microstructural units of the plasma sprayed deposit are splats, which are formed by spreading of molten particles on the substrate. Good contact between splats reduces porosity and other 
structural defects, and esults in high strength and hardness. However, poor splats contact has been observed, due to the non-uniform heating ability across the plasma stream. Particles in zones away from the stream centerline cannot be melted and cannot form the desired splats.

The deposit microstructure can be modified by incorporation of nanosize agglomerates. The nanosized powder flies in the outer zone of the stream and retains an un-melted state in the deposit. The nanoparticles bind the splats by sintering bonds. Such a structure exhibited enhanced mechanical properties.

The desired result can be achieved when most of the powder is able to fly through the plasma stream center zone. There are several factors that affect their in-flight behavior, but the most influential factor is suggested to be the carrier gas flow rate. For a specific situation, there is an optimum value. Carrier gas flow rate lower than this value cannot allow the powder reach the stream center zone, whereas carrier gas flow rate higher than this value will drive the powder over and across the center zone.

\section{References}

1. S. Sampath, R. Gansert and H. Herman; "Plasma-spray forming ceramics and layered composites"; JOM, 47 [10] 30-33 (2002).

2. A. Agaewal, T. Mckechine and S. Seal; "The spray forming of nanostructured aluminum oxide"; JOM, 54 [9] 42-44 (2002).

3. http://www.pyrogenesis.com?frame/main_sparay.htm

4. http://www.plasmapros.com/spray-formed-structures.htm

5. T. Mckechnie, P. Krotz, Y. Liaw, F. Zimmerman and R. Holmes; "Near-net shape forming of ceramic refractory composite high temperature cartridges by VPS"; Therm. Spray Ind. Appl., Proc. Natl. $7^{\text {th }}$ Therm. Spray Conf., 457-61 (1994).

6. A. Agarwal, T. McKechnie, S. Starett and M.M. Opeka; "Near net shape forming of hafnium-based ceramic components: synthesis and characterization"; Elevated Temperature Coatings: Science and Technology IV, 302-315 (2001).

7. T. Valente, C. Bartuli, G. Visconti and M. Tului; "Plasma sprayed ultra high temperature ceramics for thermal protection systems"; Thermal Spray: Surface Engineering Via Applied Research, $I^{t}$ Proceedings of the International Thermal Spray Conferenc, Montreal, QC, Canada, May 8-11, 2000, 837-841 (2000).

8. M.V. Gopalakrishnan, K. Metzgar, D. Rosetta and R. Krishnamurthy; "Structural characterisation and strength evaluation of spray formed ceramic composite near-net shapes"; Journal of Materials Processing Technology, 135 [2-3] 228-234 (2003).

9. A. Devasenapathi, H.W. Ng, S.C.M. Yu and A.B. Indra; "Forming near net shape free-standing components by plasma spraying"; Materials Letters, 57 [4], 882-886 (2002).

10. G.E. Kim, P.G. Tsantrizos, S. Grenier, A. Cavasin and T. Brzezinski; 'Near net-shape forming of thermal barrier coated components for gas turbine engine applications"; Thermal Spray: Meeting the Challenges of the 21 st Century, Proceedings of the $15^{\text {th }}$ International Thermal Spray Conference, Nice, May 25-29, 1998, 2 1229-1232 (1998).

11. http://www.gordonengland.co.uk/ps.htm.

12. J. Madejski, "Solidification of droplets on a cold substrates", Int. J. Heat Mass Transfer, 19 1009-13 (1976).

13. A. Kucuk, R.S. Lima, and C.C. Berndt; "Influence of plasma spray parameters on formation and morphology of $\mathrm{ZrO}_{2}-8$ wt\% $\mathrm{Y}_{2} \mathrm{O}_{3}$ deposits"; Journal of the American Ceramic Society, 84 [4] 693700 (2001).

14. L.L. Shaw, D. Goberman, R. Ren, M. Gell, S. Jiang, Y. Wang, T.D. Xiao and P.R. Strutt; "The dependency of microstructure and properties of nanostructured coatings on plasma spray conditions", Surf. Coat. Tech., 130 [1] 1-8 (2000). 
15. A. Kucuk, R.S. Lima, and C.C. Berndt; Influence of plasma spray parameters on in-flight characteristics of $\mathrm{ZrO}_{2}-8 \mathrm{wt} \% \mathrm{Y}_{2} \mathrm{O}_{3}$ ceramic particles"; Journal of the American Ceramic Society, 84 [4] 685-692 (2001).

16. T. J. Jewett, W. C. Smith, H. Herman, J. Margolies, and S. Sampath, "Plasma Processing of Functionally Graded Materials, Part II: Deposit Formation"; pp. 607-12 in Thermal Spray: A United Forum for Scientific and Techological Advances. Edited by C. C. Berndt. ASM International, Materials Park, OH, 1998.

17. L. Leblanc, C. Moreau, J.-G. Legoux, and B. Arsenault, "Characterization of Plasma Spray Processes by Monitoring the State of the Sprayed Particles"; pp. 329-34 in United Thermal Spray Conference1999. Edited by E. Lugscheider and P.A. Kammer. German Welding Society, Dusseldorf, Germany, 1999.

18. J. R. Fincke and W. D. Swank, "Air-Plasma Spraying of Zirconia: Spray Characteristics and Standoff Distance Effect on Deposition Efficiency and Porosity"; pp. 513-18 in Thermal Spray: International Advances in Coating Technology. Edited by C. C. Berndt. ASM International, Materiak Park, OH, 1992.

19. J. Knuuttila, P. Saarenrinne, R. Hernberg, T. Lehtinen, and T. Mantyla, "In-Situ Measurement of Particle Concentration and Velocity Using a Non-Intensified CCD Camera"; pp. 577-82 in Thermal Spray: A United Forum for Scientific and Technological Advances. Edited by C. C. Berndt. ASM International, Materials Park, OH, 1997.

20. J. Knuuttila, P. Saarenrinne, R. Hernberg, T. Lehtinen, and T. Mantyla, "In-Situ Measurement of Particle Concentration and Velocity Using a Non-Intensified CCD Camera"; pp. 577-82 in Thermal Spray: A United Forum for Scientific and Technological Advances. Edited by C. C. Berndt. ASM International, Materials Park, OH, 1997.

21. L. Leblanc, P. Gougeon, and C. Moreau, "Investigation of the Long-Term Stability of Plasma Spraying by Monitoring Characteristics of the Sprayed Particles"; pp. 567-75 in Thermal Spray: A United Forum for Scientific and Technological Advances. Edited by C. C. Berndt. ASM International, Materials Park, OH, 1997.

22. T. J. Jewett, W. C. Smith, H. Herman, J. Margolies, and S. Sampath, "Plasma Processing of Functionally Graded Materials, Part II: Deposit Formation"; pp. 607-12 in Thermal Spray: A United Forum for Scientific and Techological Advances. Edited by C. C. Berndt. ASM International, Materials Park, OH, 1998. 